\title{
Acute neuromuscular response during eccentric overload protocol by using a mechanical device to increase the load
}

\section{Resposta neuromuscular aguda durante um protocolo de sobrecarga excêntrica usando um dispositivo mecânico para aumentar a carga}

\author{
Marcel B. Lanza ${ }^{\dagger}$ \\ Antônio E.M. Pertence ${ }^{2}$ \\ André G. P. Andrade \\ Gustavo H. Peixoto ${ }^{3}$ \\ Leonardo Bonato Felix ${ }^{4}$ \\ Mauro H. Chagas ${ }^{3}$
}

\begin{abstract}
The aim of this study was to propose a mechanical device that could increase the mechanical load during the entire eccentric (ECC) action on a knee flexor machine and to compare the muscular activity when the device was used during a testing protocol. Fifteen physically active women were recruited, and they performed two protocols: control and eccentric overload. Control protocol was performed with concentric (CON) and ECC actions with similar load (60\% of one repetition maximum) whilst eccentric overload protocol consisted of ECC actions with $40 \%$ more load than CON actions. Muscular activation was measured using surface electromyography of the biceps femoris $(\mathrm{BF})$ and the gastrocnemius medialis $(\mathrm{GM})$ muscles. ECC actions presented a higher muscular activation during eccentric overload protocol than control protocol for $\mathrm{BF}(p=$ $0.032)$, but not for the GM $(p=0.439)$. The mechanical device increased the mechanical load during the ECC muscle action and consequently increased the amplitude of the neural drive to the $\mathrm{BF}$ muscle; however, it did not increase the amplitude of the neural drive to the GM muscle.
\end{abstract}

Key words: Electromyography; Muscle contraction; Resistance training.

Resumo - O objetivo deste estudo foi propor um dispositivo mecânico que acoplado a uma cadeira flexora aumente a carga mecânica durante toda a ação excêntrica (ECC) e comparar a atividade muscular durante a utilização do dispositivo proposto. Quinze mulheres fisicamente ativas foram recrutadas e realizaram dois diferentes protocolos (controle e sobrecarga ECC). $O$ protocolo controle foi realizado com açôes concêntricas (CON) e ECC com carga iguais (60\% de uma repetição máxima), enquanto o protocolo de sobrecarga $E C C$ consistiu em ações $E C C$ com $40 \%$ mais de carga do que as ações CON. A ativação muscular dos músculos biceps femoris (BF) e gastrocnemius medialis (GM) foi medida por meio de eletromiografia de superfície. Durante as ações ECC foi observada uma maior ativação do BF durante o protocolo de sobrecarga quando comparado ao protocolo controle $(p=0,032)$. No entanto, GM não apresentou diferenças na ativação entre os protocolos $(p=0,439)$. O dispositivo mecânico proposto foi capaz de aumentar a carga durante a ação ECC e, consequentemente, a atividade muscular do BF.

Palavras-chave: Contração muscular; Eletromiografia; Treinamento de resistência.
1 Loughborough University. School of Sport, Exercise and Health Sciences. Loughborough Leicestershire. United Kingdom.

2 Federal University of Minas Gerais. Mechanical Projects Laboratory. Belo Horizonte, MG. Brazil.

3 Federal University of Minas Gerais. Laboratory of Biomechanics. Belo Horizonte, MG. Brazil.

4 Federal University of Viçosa. Viçosa, MG. Brazil.

Received: 18 August 2016 Accepted: 20 July 2017 


\section{INTRODUCTION}

Distinct patterns of muscle activation and strength production between eccentric (ECC) and concentric $(\mathrm{CON})$ muscle actions have been detected during resistance training ${ }^{1-4}$ with a higher capacity to produce strength during ECC actions ${ }^{5-6}$. Training where ECC actions were overload (ECC overload [EO] training), performed with more load than during $\mathrm{CON}$ action it was verified after training an increase on the size of type IIX fibres, a higher increase at isokinetic and isometric force production ${ }^{8}$ and higher neuromuscular activation ${ }^{8-10}$. Owing to the importance of ECC actions in neuromuscular activation ${ }^{11}$ and the benefits of $\mathrm{EO}$ training, machines have been developed to increased load during the ECC action ${ }^{12-15}$.

Attempting to increase the load during the ECC action could be laborious and potentially unsafe which may lead researchers to use isokinetic dynameters when conducting their research ${ }^{8}$. However, isokinetic dynamometers require higher costs and could be expensive for training centres and gyms. In addition, during rehabilitation, the general public, athletes, or patients typically perform daily training on weight-training machines rather than isokinetic dynamometers. Thus, better understand the acute responses using weight-training machines could provide valuable information for training prescription.

EO training have been performed with flywheel machine ${ }^{15-16}$. The flywheel consists of a spinning flywheel that allows the ECC action to be performed under higher loads then the CON action. Nevertheless, the flywheel system is limited because the load during the ECC action is not constant throughout the range of motion ${ }^{17}$. A group of researchers developed a machine that allows ECC overload throughout the contraction without assistance $^{14}$; however, it was limited to a few muscle groups. Hence, a device that could change the load during the ECC action on different types of machines and throughout the range of motion could be beneficial to practitioners.

Therefore, this study contained two aims. The first was to propose a mechanical device that could increase the mechanical load during the entire ECC action on a knee flexor machine. The second aim was to compare the neuromuscular activity between an $\mathrm{EO}$ protocol and a control protocol (CO) with the designed mechanical device.

\section{METODOLOGICAL PROCEDURES}

\section{Participants}

The sample population was 15 healthy women $(21 \pm 2$ years, $159 \pm 4 \mathrm{~cm}$, $58 \pm 7 \mathrm{~kg}$ ) with no history of lower limb injury and no strength training for at least six months. The calculation of the sample size was performed with the $G^{*}$ Power 3 program ${ }^{18}$. Females were used because there are a low number of studies using this gender. The local ethics advisory committee approved the study, and the participants provided written informed consent prior to their participation. 


\section{Procedures}

Participants performed the exercise unilaterally on the seated leg-curl machine (Master Equipment, Brazil) with their dominant leg (leg used to kick a soccer ball). To verify whether the changes in mechanical resistance (i.e. resistance provide by the machine to move the load) caused by the mechanical device altered muscle activation, two different protocols, $\mathrm{EO}$ and $\mathrm{CO}$, were implemented and surface EMG (sEMG) was recorded. For the EO protocol, the mechanical resistance during the ECC action was higher than the resistance during the $\mathrm{CON}$ action; however, the $\mathrm{CO}$ protocol showed the same resistance during both contractions. The duration of the repetition, which is a factor that affects neuromuscular activation ${ }^{19}$, was used as a control variable. The total duration of the repetition was 6 s (controlled with a metronome [Metronome Plus ${ }^{\circledR}$ ]): $2 \mathrm{~s}$ for the CON action, $1 \mathrm{~s}$ for the isometric (ISO) muscle action (which was necessary to expand the mechanical device), $2 \mathrm{~s}$ for the ECC action, and finally 1 $\mathrm{s}$ for placing the mechanical device at the start position (before starting another repetition). Participants were instructed to maintain the ankle in maximum voluntary dorsiflexion during the entire knee flexion exercise.

Table 1. Configuration of the $\mathrm{CO}$ and e EO testing protocols.

\begin{tabular}{lccccc}
\hline Protocol & $\begin{array}{c}\text { Set } x \\
\text { Repetition }\end{array}$ & $\begin{array}{c}\text { CON load } \\
(\% 1 \mathrm{RM} / \text { Mean } \pm \text { SD }[\mathrm{kg}])\end{array}$ & $\begin{array}{c}\text { ECC load } \\
(\% 1 \mathrm{RM} / \text { Mean } \pm \text { SD }[\mathrm{kg}])\end{array}$ & $\begin{array}{c}\text { Duration of } \\
\text { Repetition }(\mathrm{s})\end{array}$ & $\begin{array}{c}\text { Rest } \\
(\mathrm{min})\end{array}$ \\
\hline C0 & $3 \times 8$ & $60 / 23 \pm 4$ & $60 / 23 \pm 4$ & 6 & 3 \\
E0 & $3 \times 8$ & $60 / 23 \pm 4$ & $84 / 32 \pm 5$ & 6 & 3 \\
\hline
\end{tabular}

$1 \mathrm{RM}=$ one repetition maximum, Con $=$ concentric action, and Ecc $=$ eccentric action. (mean \pm standard deviation, $\mathrm{n}=15)$.

The experimental design consisted of four sessions, where testing sessions 3 and 4 were balanced between the participants. First session consisted of $1 R M$ testing and familiarization. During second session, the $1 R M$ test and testing protocol familiarization were repeated. The $1 \mathrm{RM}$ values from the first session was used during the second session to improve the test precision. The testing protocol load was determined as a percentage of the $1 \mathrm{RM}$ test from the second session.

\section{Mechanical Device}

A mechanical device developed to change the mechanical resistance during the ECC action was integrated into a seated leg-curl machine (Master Equipment, Brazil; Figure 1). The machine's original cam was replaced with the developed mechanical device (Figure 2), and the original range of motion was maintained. 


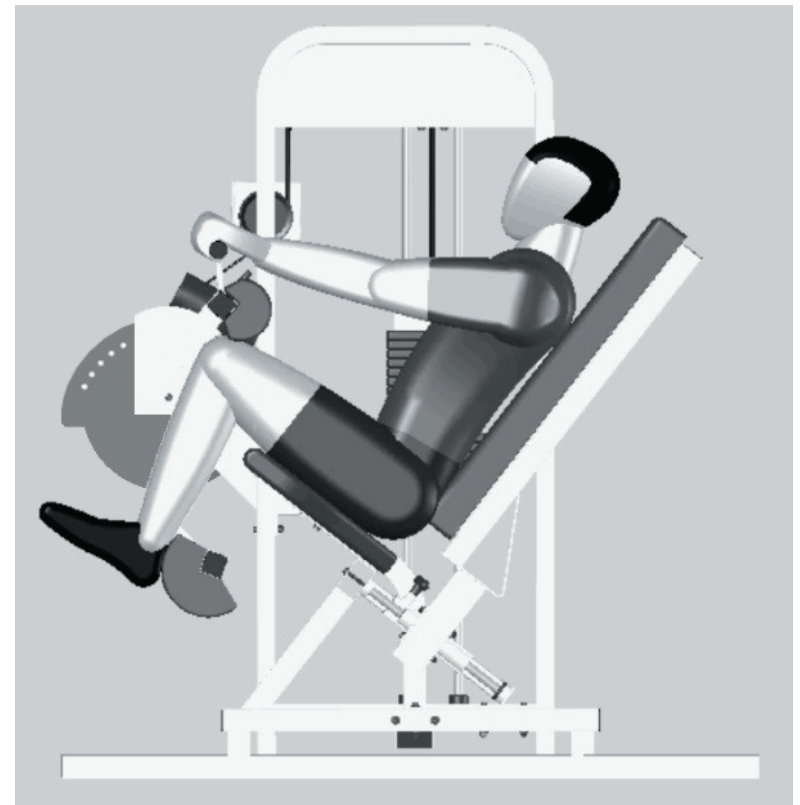

Figure 1. The figure is a Schematic design of the seated leg-curl machine used during the testing sessions

The mechanical device used an expander mechanism to increase the radius $(r ; r=100 \mathrm{~mm}$ ) which occurred over the entire ECC action (negative work), where $r$ became $r^{\prime}\left(r^{\prime}=140 \mathrm{~mm}\right)$. The expander mechanism was triggered at the end of the $\mathrm{CON}$ action (positive work; Figure 2) resulting in a higher torque for the ECC action owing to the increase of the $r$ to r' (Figure 3). When the CON action restarted, the device was returned to the original position ( $\mathrm{r}$ ). The activation of the expander mechanism (representing an 40\% increase of the load) was performed manually by the application of an external force on a lever attached to the mechanical device (Figure 2B). The changes only occurred during the EO protocol (time change was $1.1 \mathrm{~s} \pm 0.1$ ). During the $\mathrm{CO}$ protocol, the mechanism used the same $\mathrm{r}$ at $\mathrm{CON}$ and ECC to all (Figure 3). The forces produced during the $\mathrm{CON}$ and $\mathrm{ECC}$ actions for both protocols were averaged for all of the participants individually and are shown in Figure 3. The mechanical device has a patent application, from the Federal University of Minas Gerais, at the National Industrial Property Institute (INPI).

\section{Measures}

\section{- 1RM test}

The 1RM test was standardized with a maximum of six attempts and a 5-min rest between attempts. A gradual progression of the load was performed according to the perception of the examiner and volunteers. When the participants performed one repetition, a new attempt was performed to verify whether they could complete an additional repetition. If the participant succeeded in the new attempt, another attempt was performed. However, if a complete repetition was not established within six attempts, a new session was scheduled to achieve the $1 \mathrm{RM}$ test. The scores obtained during the $1 \mathrm{RM}$ test with a traditional knee-flexion exercise (without the 


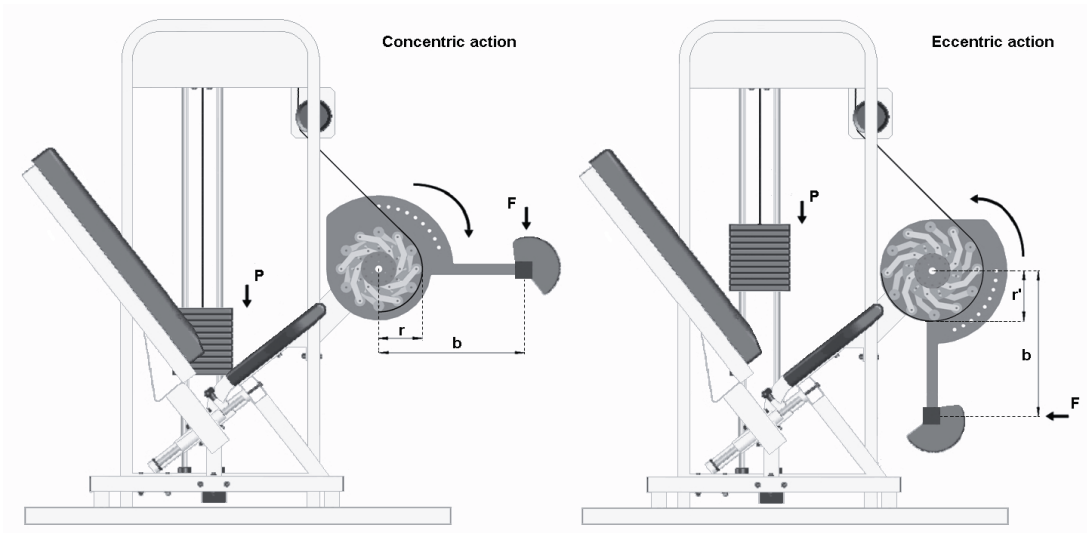

Figure 2. Schematic design of the mechanical device and expander mechanism. P represents the load being pulled; $r$ is the perpendicular distance between the cam axis and the point where the cable touches the cam; $b$ represents the distance between the axis of the cam and the lever; and $\mathrm{F}$ is the force applied by the participant. $(A)$ is the concentric action with the device in its original size; (B) is the eccentric action with the device expanded.

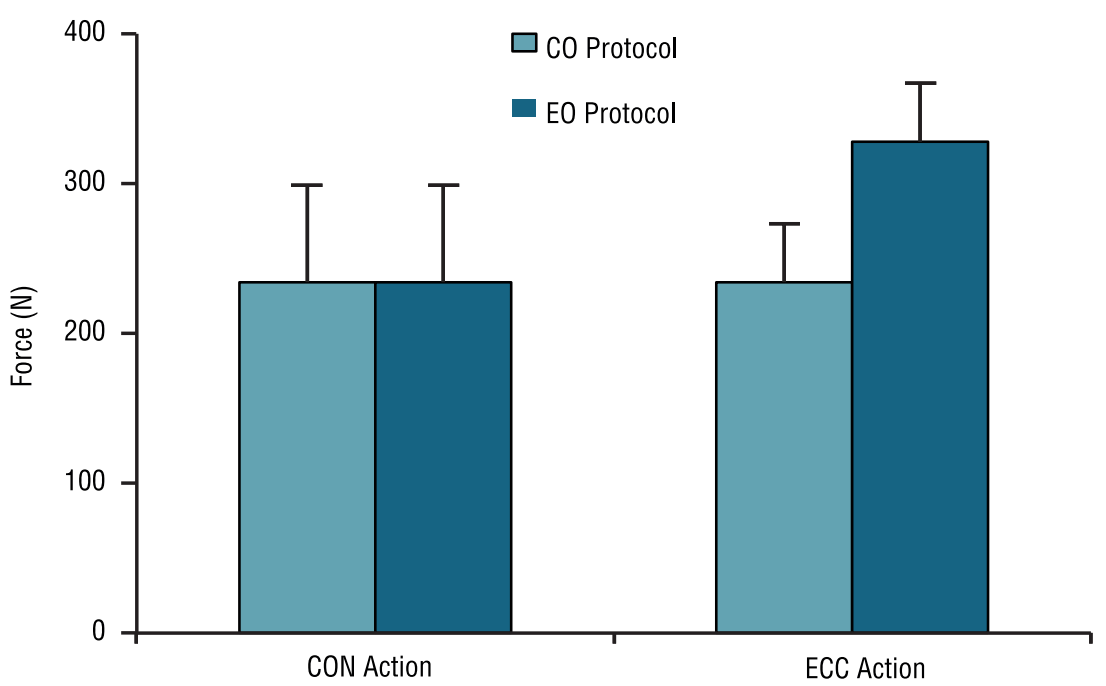

Figure 3. Force values for the concentric (CON) and eccentric (ECC) actions during the control (CO) and eccentric overload (EO) protocols, mean \pm standard deviation $(n=15)$

use of the expander mechanism) were used as a reference for the load during testing sessions 3 and 4 (see Table 1).

\section{- EMG assessment}

Surface electromyography (EMG) data were collected from the biceps femoris (BF) and the gastrocnemius medialis (GM) muscles with a Biovision ${ }^{\circledR} \mathrm{EMG}$ system. The electrode placement was based on the guidelines of the Surface Electromyography Non-Invasive Assessment of Muscle (SENIAM). The preamplified surface electrodes $(\mathrm{Ag} / \mathrm{Cl}$ with a $1-\mathrm{cm}$ diameter $)$ were placed on each muscle at a distance of $2 \mathrm{~cm}$ from the electrodes centres. Before placing the electrodes, the skin area was shaved and cleaned with isopropyl alcohol to reduce skin impedance and to ensure a good adherence of the electrodes. The EMG signal passed through differential amplifiers (x 1000) at a sample rate of $1000 \mathrm{~Hz}$. During the offline analysis, the sEMG data were filtered (6-500 Hz) using a fourth-order Butterworth band-pass filter. 
The root mean square (RMS) of the EMG signal $\left(\mathrm{RMS}_{\mathrm{EMG}}\right)$ was calculated (CON and ECC action) in the respective time window duration for each of the eight repetitions in each set. After each set, the average $\mathrm{RMS}_{\mathrm{EMG}}$ of the eight repetitions was calculated. This procedure was performed for three sets, resulting in three CON and three ECC RMSEMG mean values. The highest RMS value (peak) among the three sets was used to normalize the muscle action of each protocol ${ }^{20}$. After normalization, we calculated the average of the percentages of the 3 sets of each protocol for the CON and $\mathrm{ECC}$ actions $\left(\mathrm{EMG}_{\mathrm{MEAN}}\right)$. These procedures were performed for the $\mathrm{BF}$ and GM muscles and only normalised data is presented in the present study. An electrogoniometer (Biovision ${ }^{\circledR}$ ), positioned at the knee joint, was used to separate the muscle actions for each repetition. The duration of each muscle action was defined as the time spent between the maximum (final knee extension) and minimum (initial knee extension) angular positions. Thus, the duration of the eccentric muscle action corresponded to the period between the maximum and minimum angular positions, while the duration of the concentric muscle action corresponded to the minimum and maximum angular positions.

\section{Statistical Analysis}

The data were analysed using an IBM SPSS 22.0 (SPSS Inc., Somers, NY, USA). To analyse the EMGMEAN and duration of the repetition, a twoway ANOVA repeated measure (protocol $\mathrm{x}$ muscle action) was performed. When appropriate, follow-up analyses were performed using paired t-tests with the Bonferroni correction. The standardized effect sizes (ES; Cohen`s d) were included, and an ES < 0.2 was considered trivial; an ES $\geq 0.2$ was considered small; an ES $\geq 0.5$ was considered moderate; and an ES $\geq 0.8$ was considered large ${ }^{21}$. Alpha level was $p<0.05$ and the data ware presented as mean \pm standard deviation.

\section{RESULTS}

For the BF muscle, the main effects for the protocol $(p=0.004)$ and the muscle action $(p<0.001)$ were observed but with no significant interaction $(p=0.244)$. A post hoc test showed that $\mathrm{EO}$ protocol was higher than $\mathrm{CO}$ protocol $(p=0.004, \mathrm{ES}=0.79)$, and the $\mathrm{CON}$ action values from the $\mathrm{CO}$ and $\mathrm{EO}$ protocols were $~ 54 \%$ higher than the ECC action values from both protocols $(p<0.001, \mathrm{ES} \geq 2.40)$. In addition, ECC action during the $\mathrm{EO}$ protocol presented a higher value than the ECC action from the $\mathrm{CO}$ protocol $(p=0.032, \mathrm{ES}=1.09$; Figure 4B); however, no differences in the $\mathrm{CON}$ action values from the $\mathrm{CO}$ and $\mathrm{EO}$ protocol testing $(p=0.133$; Figure 4A) were found.

The results from the GM muscle showed no significant interaction $(p=0.956)$ and no main effect for the protocol $(p=0.206)$; however, a main effect to the muscle action type $(p<0.001)$ was shown. Post hoc test showed the $\mathrm{CON}$ action values from the $\mathrm{CO}$ testing protocol and the 
A

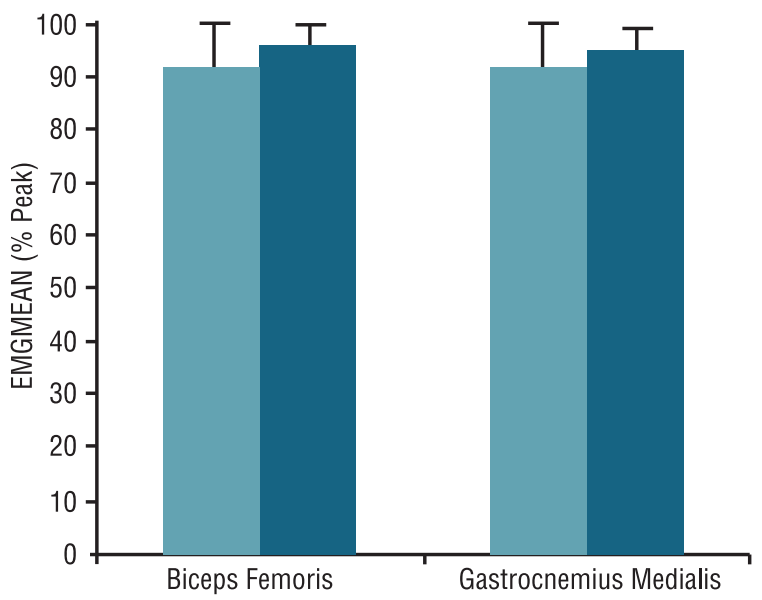

B

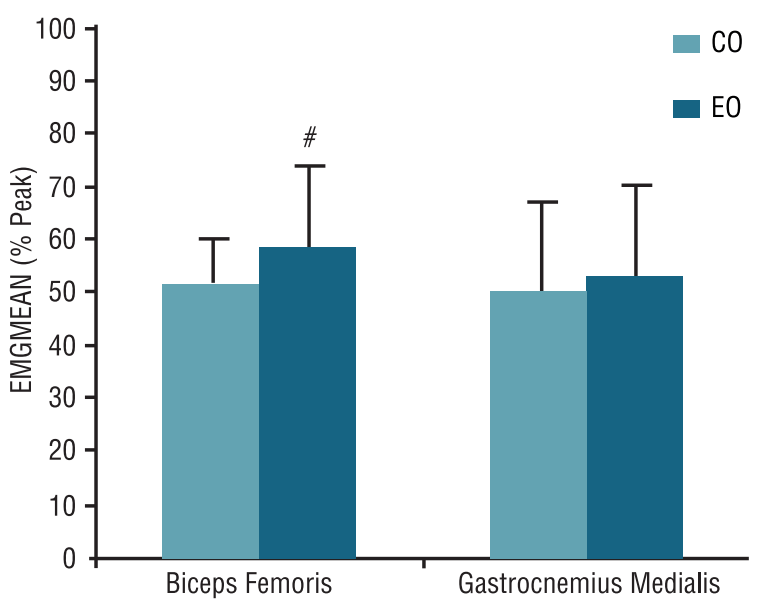

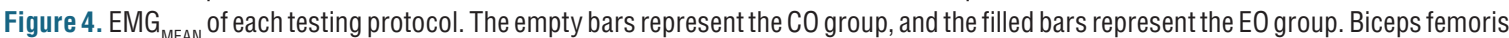
showed a main effect for protocol and action $(p \leq 0.004)$ but gastrocnemius medialis only showed a main effect for action $(p<0.001)$. The \# symbol indicates that the ECC EMG MEAN $_{\text {from the EO protocol was higher than the ECC EMG }}$ from the CO protocol $(p=0.032)$ for $B F$.

EO protocol were $~ 53$ higher than the ECC values from both protocols $(p$ $<0.001, \mathrm{ES} \leq 3.32$ ) for the same protocol. However, no differences were found in the $\mathrm{CON}$ action values for the $\mathrm{CO}$ and $\mathrm{EO}$ testing protocols. Similar results were found for the ECC actions $(p=0.366$, Figure 4A; $p$ $=0.439$, Figure 4B).

The repetition duration showed no main effect for protocol $(p=0.378)$, muscle actions $(p=0.141)$ or interaction $(p=0.095)$.

\section{DISCUSSION}

The present study has two main findings: (i) the developed device caused an increase in the lever arm of the machine, hence, resistance torque also increased creating a higher active torque during the ECC action; (ii) increased neuromuscular activation during ECC action at $\mathrm{EO}$ for $\mathrm{BF}$.

Given the higher load during ECC actions at the EO protocol, a higher neuromuscular activation would be expected ${ }^{22}$. For the BF muscle in the EO protocol, the ECC actions showed a significantly higher $\mathrm{RMS}_{\text {MEAN }}$ (16\%) than the $\mathrm{CO}$ protocol. The increases in the EMG amplitude could have occurred due to a higher MU recruitment and/or higher firing frequency of the recruited $\mathrm{MUs}^{23}$. Another explanation is the contribution of the passive elements during the ECC action to compensate the lack of the contractile materials (i.e. fewer cross bridges) ${ }^{3,24}$ which might have an effect on the neuromuscular activation.

One study investigated the acute neuromuscular effects (compared by EMG amplitude) of the EO exercise and they found contrasting finds compare to the present study ${ }^{25}$. For instance, they investigated the effects of $\mathrm{EO}$ exercise during bench press and although no differences in neuromuscular activation were found for pectoralis major and triceps brachii greater activation during ECC action overload was observed for the anterior deltoid muscle in the same study. Different methodology was used 
compared to the present study, but possible differences could be related to the multi-joint exercise bench press characteristics which may allow different neural strategies than the uniarticular exercise ${ }^{26}$. Also the function of the different muscles (i.e. agonist, stabilizer) may had an impact on the results $^{25}$; however, further clarification is required.

Neuromuscular activation observed in the GM muscle was similar to the $\mathrm{BF}$ muscle in the present study, which showed a strong synergistic action during knee flexion. Owing to the high synergistic action of the GM muscle and the $40 \%$ increase in the mechanical load, a difference between the protocols during the ECC action was expected. This lack of difference could be due to synergistic muscles may contribute to a different magnitude ${ }^{26}$. Previously, sartorius and gracilis muscles neuromuscular activation was analysed during knee flexion, and greater activation of the gracilis than the sartorius was found ${ }^{26}$. There is little information in the literature regarding the level of contribution of each synergist muscle during the knee flexion, hindering the understanding of the impact of an EO protocol. The increased mechanical load during the ECC action may have been distributed unevenly across the synergist muscles. In addition, the different force produced by the GM muscle during knee flexion might also have an influence. It is expected from GM muscle contributed to a higher torque output when the knee was extended at the end of the ECC muscle action $^{27}$. Thus, perhaps an extent of the neural drive to the GM muscle was masked because the analysis of the neuromuscular responses was carried out for the full range of motion and not the final angles of the kneeflexion.

As a limitation, this study only analysed BF and GM muscles and as previously reported various muscles can exert a synergistic action during knee flexion along with the agonist muscles ${ }^{26-28}$. Additionally, the manual alteration of the mechanical device during the EO protocol must be considered. Although increasing the load during the ECC action required external assistance and the procedure was secure and safe, $1 \mathrm{~s}$ was required to alter the device, which also was add to the $\mathrm{CO}$ protocol. A longer repetition time in one protocol could result in a higher time under tension and, consequently, a higher neuromuscular demand. However, no difference in time length to expand the device was observed between the protocols $(\mathrm{P}=0.875)$.

Further research will be necessary to investigate the neuromuscular activation over different muscle groups with ECC overload. We suggest using a rating of perceived exertion scale during protocols what maybe could be useful tool during the test sessions. From a practical perspective, we suggest an improvement to the device that would allow the practitioner to perform the mechanical change to overload the ECC action, avoiding external assistance and increasing the device efficiency.

\section{CONCLUSION}

In conclusion, the mechanical device increased the mechanical load during the ECC muscle action and consequently increased the amplitude of the 
neural drive to the $\mathrm{BF}$ muscle; however, it did not increase the amplitude of the neural drive to the GM muscle. The device demonstrated a valid alternative for increasing neuromuscular activation during ECC action, which could be used as a new method for varying a training program during resistance training protocols with knee flexion.

\section{Acknowledgments}

This study received from the FAPEMIG, CAPES (Brazil), and PRPq of the Federal University of Minas Gerais.

\section{REFERENCES}

1. Andersen LL, Andersen JL, Magnusson SP, Aagaard P. Neuromuscular adaptations to detraining following resistance training in previously untrained subjects. Eur J Appl Physiol 2005;93(5-6):511-8.

2. Duchateau J, Enoka RM. Neural control of shortening and lengthening contractions: influence of task constraints. J Physiol 2008;586(Pt 24):5853-64.

3. Fang Y, Siemionow V, Sahgal V, Xiong F, Yue GH. Distinct brain activation patterns for human maximal voluntary eccentric and concentric muscle actions. Brain Res 2004;1023(2):200-12.

4. Pincivero DM, Salfetnikov Y, Campy RM, Coelho AJ. Angle- and gender-specific quadriceps femoris muscle recruitment and knee extensor torque. J Biomech 2004;37(11):1689-97.

5. Roig M, O'Brien K, Kirk G, Murray R, McKinnon P, Shadgan B, et al. The effects of eccentric versus concentric resistance training on muscle strength and mass in healthy adults: a systematic review with meta-analysis. Br J Sports Med 2009;43(8):556-68.

6. Enoka RM. Eccentric contractions require unique activation strategies by the nervous system. J Appl Physiol 1996;81(6):2339-46.

7. Friedmann-Bette B, Bauer T, Kinscherf R, Vorwald S, Klute K, Bischoff D, et al. Effects of strength training with eccentric overload on muscle adaptation in male athletes. Eur J Appl Physiol 2010;108(4):821-36.

8. Hortobágyi T, DeVita P. Favorable neuromuscular and cardiovascular responses to 7 days of exercise with an eccentric overload in elderly women. J Gerontol A Biol Sci Med Sci 2000;55(8):B401-10.

9. Kingma JJ, de Knikker R, Wittink HM, Takken T. Eccentric overload training in patients with chronic Achilles tendinopathy: a systematic review. Br J Sports Med 2007;41(6):e3.

10. Ojasto T, Hakkinen K. Effects of different accentuated eccentric loads on acute neuromuscular, growth hormone, and blood lactate responses during a hypertrophic protocol. J Strength Cond Res 2009;23(3):946-53.

11. Dudley GA, Tesch PA, Miller BJ, Buchanan P. Importance of eccentric actions in performance adaptations to resistance training. Aviat Space Environ Med 1991:62(6):543-50.

12. Tesch PA, Ekberg A, Lindquist DM, Trieschmann JT. Muscle hypertrophy following 5-week resistance training using a non-gravity-dependent exercise system. Acta Physiol Scand 2004;180(1):89-98.

13. Doan BK, Newton RU, Marsit JL, Triplett-McBride NT, Koziris LP, Fry AC, et al. Effects of increased eccentric loading on bench press 1RM. J Strength Cond Res 2002;16(1):9-13.

14. Frohm A, Halvorsen K, Thorstensson A. A new device for controlled eccentric overloading in training and rehabilitation. Eur J Appl Physiol 2005;94(1-2):168-74. 
15. Tous-Fajardo J, Maldonado RA, Quintana JM, Pozzo M, Tesch PA. The flywheel leg-curl machine: offering eccentric overload for hamstring development. Int J Sports Physiol Perform 2006;1(3):293-8.

16. Norrbrand L, Fluckey J, Pozzo M, Tesch P. Resistance training using eccentric overload induces early adaptations in skeletal muscle size. Eur J Appl Physiol 2008;102(3):271-81.

17. Norrbrand L, Pozzo M, Tesch PA. Flywheel resistance training calls for greater eccentric muscle activation than weight training. Eur J Appl Physiol 2010;110(5):997-1005.

18. Faul F, Erdfelder E, Lang A, Buchner A. G* Power 3: A flexible statistical power analysis program for the social, behavioral, and biomedical sciences. Behav Res Methods 2007; 39(2):175-191.

19. Lacerda LT, Martins-Costa HC, Diniz RC, Lima FV, Andrade AG, Tourino FD, et al. Variations in repetition duration and repetition numbers influence muscular activation and blood lactate response in protocols equalized by time under tension. J Strength Cond Res 2016;30(1):251-8.

20. Burden A. How should we normalize electromyograms obtained from healthy participants? What we have learned from over 25 years of research. J Electromyogr Kinesiol 2010;20(6):1023-35.

21. Cohen J. Statistical power analysis for the behavioural sciences. Hillsdale: Lawrence Erlbaum Associates; 1988.

22. Linnamo V, Moritani T, Nicol C, Komi P V. Motor unit activation patterns during isometric, concentric and eccentric actions at different force levels. J Electromyogr Kinesiol 2003 Feb;13(1):93-101.

23. Duchateau J, Baudry S. Maximal discharge rate of motor units determines the maximal rate of force development during ballistic contractions in human [Internet]. Front in Hum Neurosci 2014 Apr;22(8):1-3.

24. Herzog W, Schachar R, Leonard TR. Characterization of the passive component of force enhancement following active stretching of skeletal muscle. J Exp Biol 2003;206(20):3635-43.

25. Ojasto T, Hakkinen K. Effects of different accentuated eccentric load levels in eccentric-concentric actions on acute neuromuscular, maximal force, and power responses. J Strength Cond Res 2009;23(3):996-1004.

26. Mohamed O, Perry J, Hislop H. Relationship between wire EMG activity, muscle length, and torque of the hamstrings. Clin Biomech 2002;17(8):569-79.

27. Kawakami Y, Amemiya K, Kanehisa H, Ikegawa S, Fukunaga T. Fatigue responses of human triceps surae muscles during repetitive maximal isometric contractions. J Appl Physiol 2000;88(6):1969-75.

28. Baratta R, Solomonow M, Zhou BH, Letson D, Chuinard R, D'Ambrosia R. Muscular coactivation. The role of the antagonist musculature in maintaining knee stability. Am J Sports Med1988;16(2):113-22.

\section{CORRESPONDING AUTHOR}

Marcel B. Lanza Neuromuscular Function Lab, Loughborough University, Epinal Way, Loughborough Leicestershire, UK LE11 3TU, United Kingdom. Email:marcel.lanza@gmail.com 